\title{
An improved method for culturing patient-derived colorectal cancer spheroids
}

\author{
Hiroyuki Miyoshi' ${ }^{1,3}$, Hisatsugu Maekawa ${ }^{1,2}$, Fumihiko Kakizaki ${ }^{1}$, Tadayoshi \\ Yamaura ${ }^{1,2}$, Kenji Kawada ${ }^{2}$, Yoshiharu Sakai ${ }^{2}$ and M. Mark Taketo ${ }^{1,3}$ \\ ${ }^{1}$ Division of Experimental Therapeutics, Graduate School of Medicine, Kyoto University, Yoshida-Konoé-cho, Sakyo-ku, Kyoto \\ 606-8501, Japan \\ ${ }^{2}$ Department of Surgery, Graduate School of Medicine, Kyoto University, Shogoin-Kawahara-cho, Sakyo-ku, Kyoto 606-8507, \\ Japan \\ ${ }^{3}$ Office of Society-Academia Collaboration for Innovation, Kyoto University, Yoshida-Honmachi, Sakyo-ku, Kyoto 606-8501, \\ Japan
}

Correspondence to: M. Mark Taketo, email: taketo@mfour.med.kyoto-u.ac.jp

Keywords: colorectal cancer; spheroid; chemical screening; cancer stem cell; tumor-initiating cell

Received: December 21, $2017 \quad$ Accepted: March 28, $2018 \quad$ Published: April 24, 2018

Copyright: Miyoshi et al. This is an open-access article distributed under the terms of the Creative Commons Attribution License 3.0 (CC BY 3.0), which permits unrestricted use, distribution, and reproduction in any medium, provided the original author and source are credited.

\section{ABSTRACT}

Recent advances allowed culturing and examination of patient-derived colorectal cancer (PD-CRC) cells as organoids or spheroids. To be applied to practical personalized medicine, however, current methods still need to be strengthened for higher efficiency. Here we report an improved method to propagate PD-CRC tumor initiating cells (TICs) in spheroid culture. We established $>100$ cancer spheroid lines derived from independent colorectal cancer patients employing a serum-containing medium with additional inhibitors, Y27632 and SB431542. Because colorectal cancer spheroids showed wide-range growth rates depending on the patient tumors, we searched for supplementary factors that accelerated proliferation of slow-growing CRC-TIC spheroids. To this end, we introduced a convenient growth-monitoring method using a luciferase reporter. We found that epidermal growth factor (EGF) and/or basic fibroblast growth factor (bFGF) were critical for steady propagation of a subset of CRC-TIC spheroids carrying the wild-type RAS and RAF genes. We also identified 5'-( $\mathrm{N}$-ethyl-carboxamido)-adenosine (NECA), an adenosine receptor agonist, as an essential supplement for another subset of spheroids. Based on these results, we propose to optimize culture conditions for CRC-TIC spheroids by adjusting to the respective tumor samples. Our method provides a versatile tool that can be applied to personalized chemotherapy evaluation in prospective clinical studies.

\section{INTRODUCTION}

Colorectal cancer is one of the commonest cancers worldwide [1]. Although the mortality of colorectal cancer is decreasing thanks to early detection efforts and treatment improvements, the disease is often lethal once it reaches the metastatic stage, even with molecular-targeted therapeutics such as antibodies against epidermal growth factor receptor (EGFR) and/or against vascular endothelial growth factor (VEGF) [2]. Furthermore, therapies remain to be developed that target the three commonly mutated gene products, APC, p53, and KRAS [3]. Recently, the "precision medicine" or "personalized approach" was introduced in order to improve the current colorectal cancer treatment. While the next generation sequencing technology has enabled us to identify the genetic changes in individual cancer cases [3], it is still challenging to predict therapeutic efficacies based on such information because of the diversity in genetic mutations and unknown epigenetic changes in each patient tumor $[4,5]$. 
Alternatively, patient-derived xenografts (PDXs) have been employed to search for efficacious personalized therapies [6,7]. Yet, it takes $1-4$ months to establish the primary PDXs, and needs additional passages to expand them for the drug sensitivity tests [8]. It has become a practical alternative to culture patient-derived tumor initiating cells of the colorectal cancer (PD-CRC-TICs) as organoids or spheroids [9-12]. However, their clinical applications have been hampered by some technical difficulties, including the requirement for supplements such as growth factors, minerals, vitamins, and hormones. To propagate tissue-derived intestinal epithelial cells rapidly, a recent method employed a serum-containing medium conditioned by L-WRN fibroblasts that secrete three components (Wnt3a, R-spondin 3, and Noggin) essential for tissue stem cells [13]. Such media can support the proliferation of various types of epithelial stem cells from humans and mice when supplemented with a Rho-associated coiled-coil protein kinase (ROCK) inhibitor, Y27632, and a transforming growth factor $\beta$ (TGF- $\beta$ ) type I receptor inhibitor, SB431542 [14].

In the present study, we have employed a serumcontaining medium supplemented with the above two inhibitors (Y27632 and SB431542), and cultured PDCRC-TICs as epithelial spheroids. We have established CRC-TIC spheroid lines that can be stored and utilized for further genetic and pharmacological analyses. We have also developed a convenient growth-monitoring method for human colonic spheroids, and identified novel supplementary factors that improved the proliferation of some slow-growing spheroid lines.

\section{RESULTS}

\section{A simple medium helps propagate patient- derived colorectal cancer spheroids}

To culture patient-derived tumor initiating cell spheroids of the colorectal cancer (PD-CRCTIC spheroids), we prepared "the cancer medium" in which the basal medium (Advanced DMEM/F12) was supplemented with FBS (5\%) and two inhibitors, Y27632 and SB431542. For spheroids of the normal colonic epithelium from the same patients, we also prepared "the eL-WRN medium" ("e" for enhanced) by supplementing the L-WRN conditioned medium with above two inhibitors [15]. We attempted to culture 148 colorectal cancer samples from 141 patients. Pathologically, they were classified as low-grade (138/148), highgrade $(5 / 148)$, or mucinous $(5 / 148)$ adenocarcinomas according to the standard histological criteria $[16,17]$. As anticipated, the histological features of the cancer epithelium coincided well between the primary tumors and their spheroids (Figure 1). To characterize the key genetic mutations, we sequenced the genomic regions of 36 CRC-TIC spheroid lines covering mutational hot spots of 50 cancer-related genes (Supplementary Figure 1). Our overall success rate for establishing colorectal cancer spheroids was $73 \%$ (108/148), whereas that for normal epithelial stem cells was $93 \%$ (124/134). Notably, our success rate for 24 cases in the latest quarter reached $88 \%$ (Table 1; see below and Discussion). The reasons for unsuccessful CRC-TIC spheroid culture included contamination by microorganisms (bacteria or yeasts; 4 cases), apparent cell damage by radiation therapy before
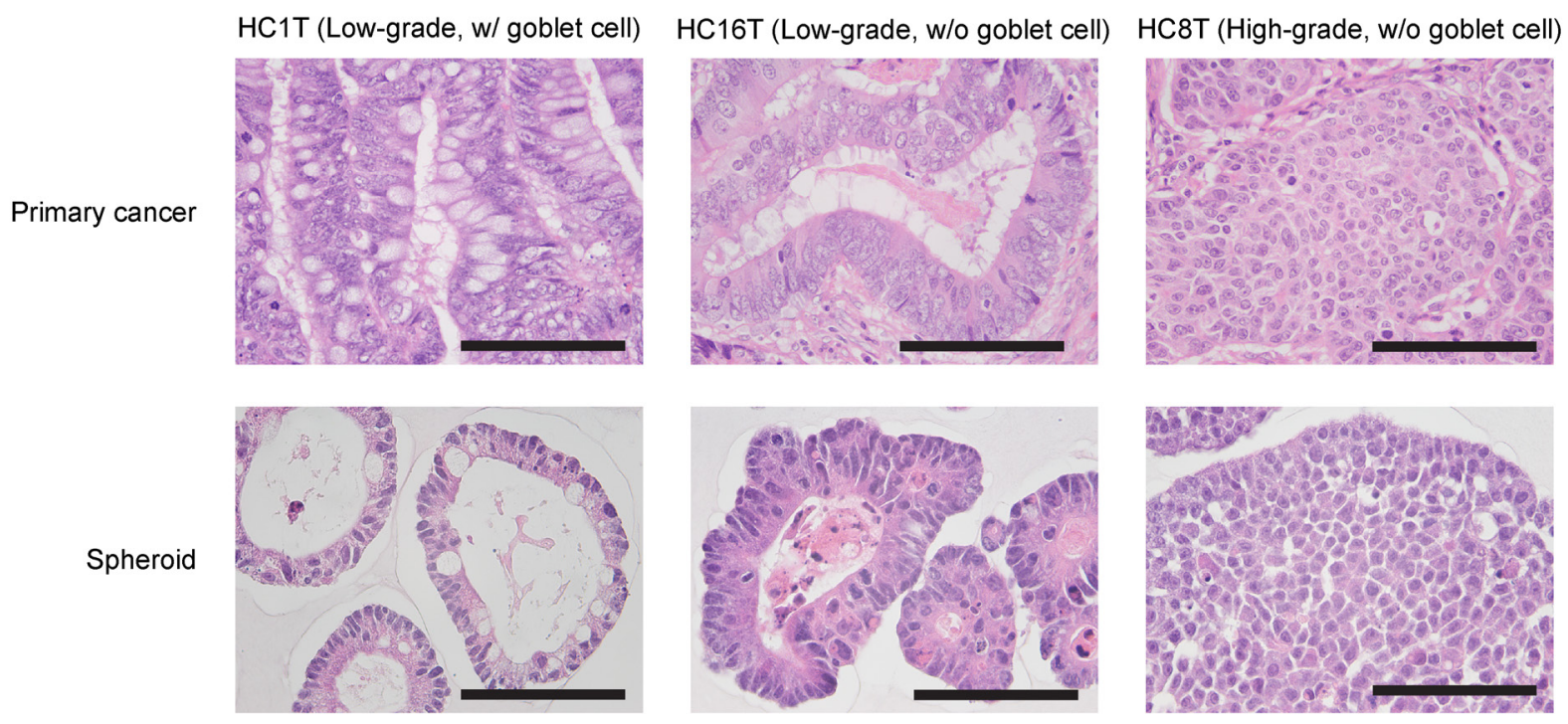

Figure 1: Histological characterization of patient-derived CRC-TIC spheroids. Shown are pairs of H\&E-stained specimens of the primary tumors (top) and spheroids (bottom) derived from the same patients. There were three representative histotypes; well-differentiated types, with (left) and without (center) mature goblet cells, and a poorly-differentiated type (right). Scale bar, $100 \mu \mathrm{m}$. 
Table 1: Success rates for establishing CRC-TIC spheroid culture scored by period

\begin{tabular}{|c|c|c|c|c|c|}
\hline Period & $\begin{array}{c}11 / 13 / 2014- \\
6 / 30 / 2015\end{array}$ & $\begin{array}{c}7 / 1 / 2015- \\
12 / 31 / 2015\end{array}$ & $\begin{array}{l}1 / 1 / 2016- \\
6 / 30 / 2016\end{array}$ & $\begin{array}{c}7 / 1 / 2016- \\
12 / 31 / 2016\end{array}$ & $\begin{array}{l}\text { 1/1/2017- } \\
3 / 31 / 2017\end{array}$ \\
\hline Total attempts & 22 & 45 & 34 & 23 & 24 \\
\hline${ }^{*}$ Success $(\%)$ & $14(64 \%)$ & $31(69 \%)$ & $26(76 \%)$ & $16(70 \%)$ & $21(88 \%)$ \\
\hline
\end{tabular}

* Numbers of colorectal cancer samples from which spheroid lines were successfully established.

Table 2: Tumor stages of primary colorectal cancer samples

\begin{tabular}{lccccc}
\hline Stage & I & II & III & IV & Total \\
\hline Number & 17 & 64 & 48 & 19 & 148 \\
${ }^{*}$ Success (\%) & $15(88 \%)$ & $42(66 \%)$ & $37(77 \%)$ & $14(74 \%)$ & $108(73 \%)$ \\
\hline
\end{tabular}

* Numbers of colorectal cancer samples from which spheroid lines were successfully established.

surgery ( 2 cases), and poor cell growth followed by cell death in early passages (of unknown causes; 34 cases) (see Discussion). We found no statistical correlations between the success rates and tumor stages (Table 2).

\section{Introduction of luciferase enables monitoring of precise spheroid growth rates}

We noticed that individual cancer spheroid lines varied widely in growth rate in vitro. However, it was difficult to determine cell number in $3 \mathrm{D}$ culture. It was also technically challenging to distribute the spheroid cells equally to multiple culture wells because trypsinized spheroids contained cell aggregates of various sizes, causing wide statistical errors in quantifications such as MTT assays. To minimize such errors, we employed a method which canceled out the variations in the initial cell numbers. Practically, we utilized spheroids infected with a lentivirus containing a luciferase expression vector driven by the CAG promoter [18]. Because its high efficiency of infection eliminated the necessity to enrich expressor subpopulations [15], we passaged post-infection spheroids 2-3 times without subcloning, and directly subjected them to cell growth assays. We monitored the growth of the normal and cancer spheroid lines daily from post-passage days 1 to 4 (Figure 2A). As shown in Figure 2B, bioluminescence levels among 16 replicated wells varied rather widely, reflecting differences in the initial cell numbers (coefficient of variation, 6.5-7.6\%). However, when calibrated to the initial photon counts on day 1 , the variations were reduced to $1.6-3.2 \%$ (Figure $2 \mathrm{C}$ ). Thus, the present method provides a highly reproducible alternative to celldisruptive methods. Accordingly, we have established a reliable method to monitor human CRC-TIC spheroid growth which can be performed with a small number of replicates.

\section{EGF and bFGF can stimulate the growth of CRC-TIC spheroid subpopulations}

EGF and bFGF have been frequently added to nonserum culture media to support the cell growth of various types [19]. However, it was unclear whether they helped spheroid proliferation in our serum-containing cancer medium. To investigate this issue, we cultured with EGF and/or bFGF four slow-growing CRC-TIC spheroid lines that carried wild-type $R A S / R A F$ genes. Because EGF/bFGF facilitated the growths of these spheroid lines substantially (Figure 3A), we then quantified their effects by the luminescence-based growth monitoring. To calibrate the effects, we introduced the growth effect index (GEI) defined as the relative growth rate of a treated group to that of its solvent-only control in each paired assay. We found that additions of both EGF and bFGF more than doubled the GEI in all four spheroid lines carrying wildtype $R A S / R A F$ (Figure 3B and Supplementary Figure 2A). Notably, the extents of growth promotion by EGF and/ or bFGF were different depending on the spheroid line carrying wild-type $R A S / R A F$. In two lines (HC6T and HC9T), bFGF was more effective than EGF, whereas in another $(\mathrm{HC} 11 \mathrm{~T})$, vice versa (Figure 3B). In another spheroid line (HC21T), the effects were similar between the two growth factors (Figure 3B). As anticipated, EGF/ bFGF showed only limited growth-promoting effects on three spheroid lines that carried $R A S$ or $R A F$ mutations $(<55 \%$ increases by both; Figure $3 \mathrm{C}$ and Supplementary Figure 2B). Interestingly, EGF and bFGF doubled the growth of normal epithelial stem cell (SC) spheroids, too (Figure 3D and Supplementary Figure 1C). Consistent with a previous report [20], four of ten spheroid lines showed gain of the FGF9 chromosomal region (Figure $3 \mathrm{E}$ ), which may explain better GEI by bFGF at least in two spheroid lines (HC6T and HC9T) compared with those in normal spheroids. However, copy number alterations 
of FGF receptor genes were not correlated with bFGF sensitivity (Figure 3E).

\section{Cell autonomous activity of the canonical Wnt signaling does not necessarily correlate with mitotic activity in CRC-TIC spheroid lines}

The canonical Wnt signaling plays crucial roles in the proliferation of CRC-TICs although they require no exogenous Wnt ligands due to mutations in the $A P C$ or $\beta$-catenin gene [21]. The strength of cell-autonomous growth signals can vary depending on the mutations or epigenetic changes in individual colorectal cancer cases, which may explain why some spheroid lines were difficult to be maintained even in the presence of EGF and bFGF. Thus, we hypothesized that the canonical Wnt signaling activity was weak in such spheroid lines, and determined the levels of MKI67 (Ki-67) and AXIN2 mRNA in our spheroid lines by qRT-PCR analyses, because $A X I N 2$ is an exclusive target of the canonical Wnt signaling pathway $[13,15,22,23]$. Surprisingly, three slow-growing spheroid lines with low MKI67 levels expressed even higher levels of AXIN2 mRNA than the normal colonic SCs (Figure $4 \mathrm{~A}, 4 \mathrm{~B}$ ), excluding the possibility that their growth was compromised by weak canonical Wnt signaling.

\section{Chemical library screening identified candidates for growth-promoting supplements}

To find additional supplementary factors that could promote spheroid growths, we screened 80 pharmacologic agonists/activators for growth-promoting effects on three luciferase-expressing CRC-TIC spheroid lines with moderate growth rates (i.e., 3-4 times in 3 days). We identified eleven compounds that stimulated spheroid growths by $>25 \%$ (Figure 5A, 5B). These included four peroxisome proliferator-activated receptor (PPAR) agonists, two adenosine receptor (AR) agonists, and two calcium-activated potassium-channel $(\mathrm{KCa})$ activators (Figure 6A). We then performed titration experiments for GW0742 (PPAR $\delta$ agonist), 5'-( $N$-ethyl-carboxamido)adenosine (NECA, non-selective AR agonist), and SKA-
A
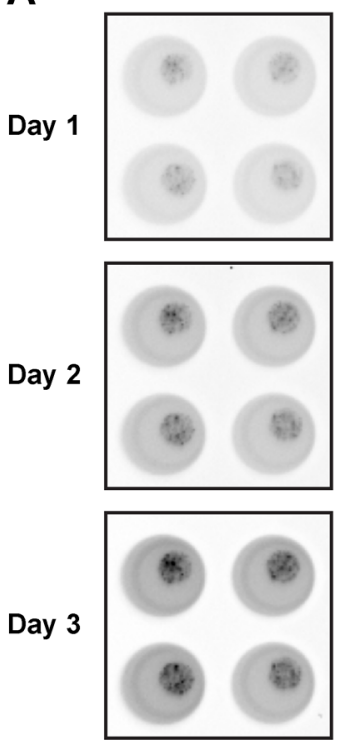

Day 4

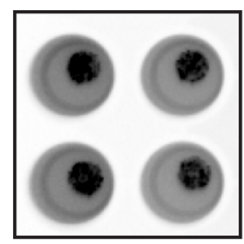

B

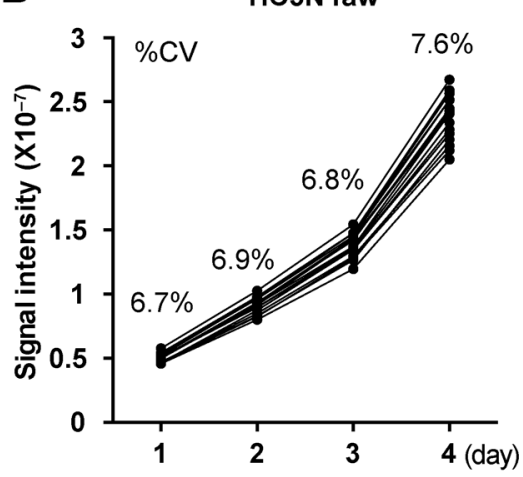

C

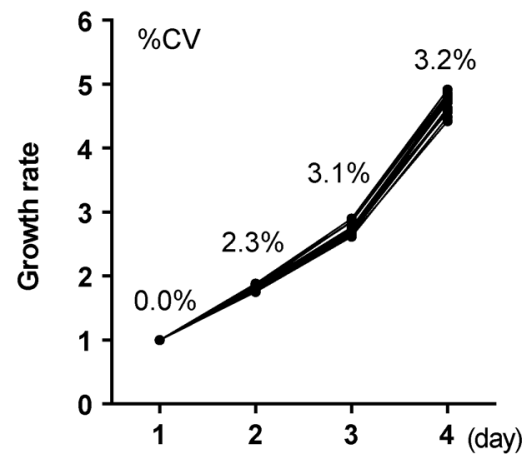

HC5T raw

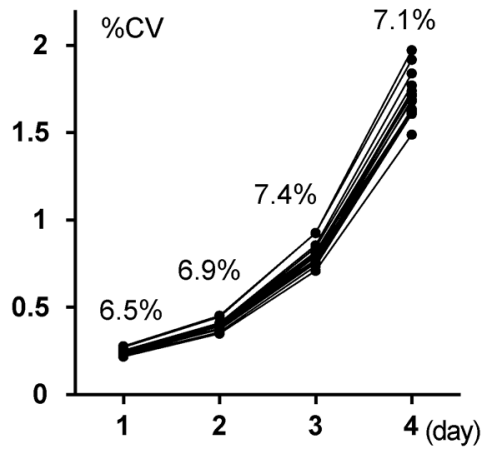

HC5T adjusted

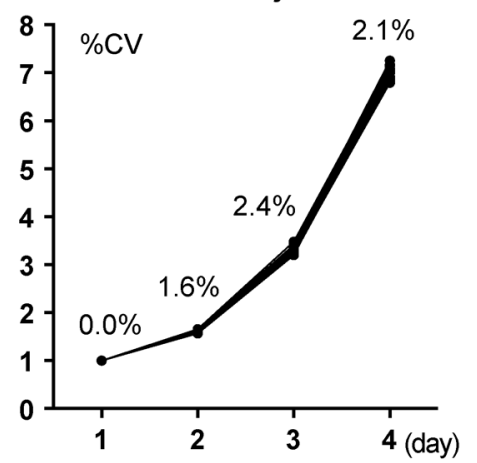

Figure 2: An accurate growth-monitoring method for human spheroids. (A) Quantitative presentation of bioluminescence from luciferase-expressing spheroids from days 1 to 4 after passages into the wells of a 96-well cell culture plate. The gray level in each well represents direct photon counts for the spheroids embedded in the corresponding Matrigel drop. The total luminescence represents the cell number in each well. (B, C) Growth monitoring of luciferase-expressing spheroids. Photon counts from spheroid lines derived from normal (HC3N raw; left) and cancer (HC5T raw; right) SCs were scored daily during post-passage days 1-4 (B). Graphs in (C) show growth rates calibrated to the initial cell numbers based on the photon counts on day 1. Sixteen replicated wells were tested for each line. The coefficient of variation $(\% \mathrm{CV})$ is shown for each data point. 

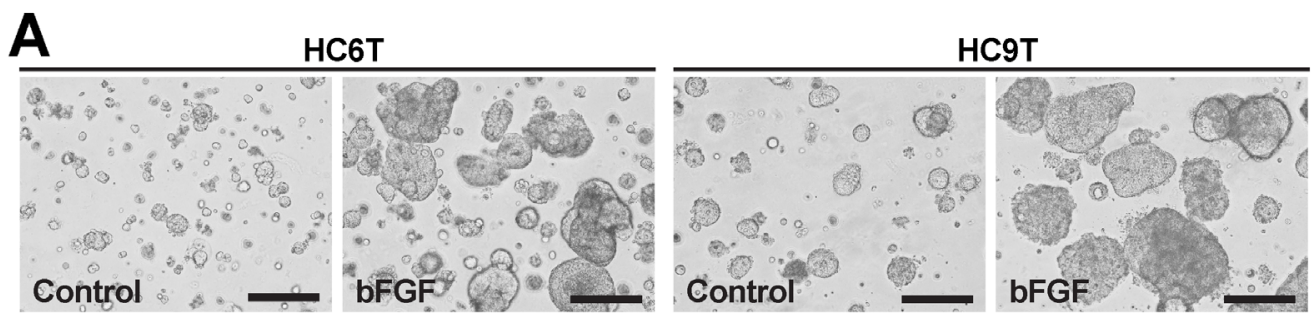

HC11T
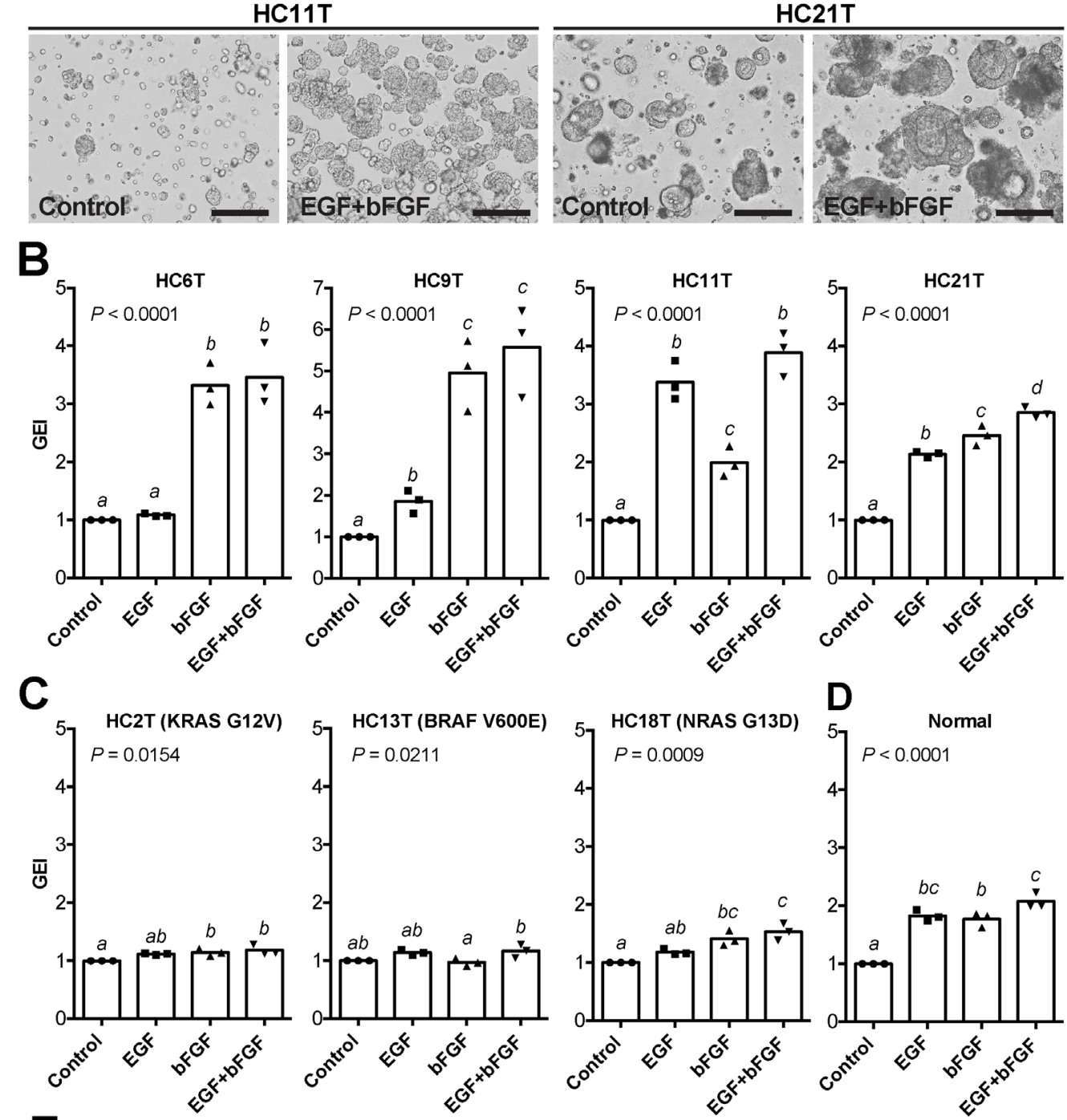

E

\begin{tabular}{|c|c|c|c|c|c|c|c|c|c|c|c|}
\hline Chr & Gene & HC1T & HC2T & HC3T & HC4T & HC5T & HC6T & HC7T & HC8T & HC9T & HC10T \\
\hline 13 & FGF9 & 2.0 & 2.0 & 1.4 & 2.0 & 2.9 & 3.0 & 2.8 & 2.0 & 3.9 & 2.0 \\
\hline 8 & FGFR1 & 2.5 & 2.0 & 5.3 & 2.0 & 1.1 & 1.5 & 2.0 & 2.0 & 2.4 & 2.0 \\
\hline 10 & FGFR2 & 2.0 & 2.0 & 2.0 & 2.0 & 2.4 & 1.5 & 2.0 & 2.0 & 2.0 & 2.0 \\
\hline 4 & FGFR3 & 2.0 & 2.0 & 2.0 & 2.0 & 2.0 & 1.4 & 1.6 & 2.0 & 1.2 & 2.0 \\
\hline 5 & FGFR4 & 2.5 & 2.4 & 2.0 & 2.0 & 2.0 & 2.0 & 2.6 & 2.0 & 1.6 & 2.0 \\
\hline
\end{tabular}

Figure 3: Growth-promoting effects of EGF and bFGF on CRC-TIC spheroids. (A) Representative phase-contrast micrographs of four cancer spheroid lines cultured in the presence of EGF and/or bFGF for 8 days. Scale bar, $200 \mu \mathrm{m}$. (B) Growth effect indices (GEI) of CRC-TIC spheroid lines carrying the wild-type $R A S / R A F$ genes. (C) GEI of the spheroid lines carrying mutant $R A S / R A F$ genes. (D) GEI of normal colonic epithelial SC spheroids. Plotted are the GEI with means in three independent experiments (B and C) or spheroid lines (D). Data were analyzed using one-way ANOVA ( $P$ values are shown in the graphs) followed by Tukey's post-test. The statistical significance between the mean values are indicated by $a, b, c$, and $d$; the value differences between different letters are statistically significant $(P<0.05)$, whereas those between the same are not. (E) Copy numbers of the FGF9, FGFR1, FGFR2, FGFR3, and FGFR4 gene loci in ten CRC-TIC-spheroid lines. Gain (blue) or loss (red) of the chromosomal region was determined relative to the control genomic DNA. 
31 (activator of $\mathrm{KCa} 2$ and $\mathrm{KCa} 3.1 \mathrm{a}$ ). While NECA exhibited a strong activity of growth promotion $\left(\mathrm{EC}_{50}=\right.$ 63.1 and $195 \mathrm{nM}$ with HC18T and HC21T spheroid lines, respectively), other two compounds showed significant effects only at the maximum dose of $10 \mu \mathrm{M}$ (Figure 6B). We also confirmed that another AR agonist, CV1808 (2-phenylaminoadenosine), showed a growth-promoting effect though weaker than that of NECA (Supplementary Figure 3A). These results suggest that NECA is a candidate suitable for CRC-TIC spheroid cultures. Notably, dosedependent responses for NECA in three independent experiments were highly reproducible (Supplementary Figure 3B), underscoring the reliability of our spheroid culture in drug-sensitivity tests.

\section{NECA supports CRC-TIC spheroid growth through cAMP-PKA signaling pathway}

Because $A_{2 B}$ is the only adenosine receptor expressed in the colonic epithelium, NECA appears to stimulate the cyclic AMP (cAMP)-protein kinase A (PKA) signaling in these cells [24]. Consistently, NECA as well as CV1808 induced morphological changes in spheroids characterized by cell flattening and increased sphere size, similar to those in forskolin-treated spheroids (Figure 6C and Supplementary Figure 3C) [25]. The growth-promoting effect of NECA was specifically antagonized by two $\mathrm{A}_{2 \mathrm{~B}}{ }^{-}$ specific inhibitors, PSB 0788 and MRS $1706\left(\mathrm{IC}_{50}=8.32\right.$ and $210 \mathrm{nM}$ with HC21T spheroid line, respectively; Figure 6D, 6E, and Supplementary Figure 3D).

To evaluate NECA further, we applied the NECAcontaining medium to three slow-growing spheroid lines with which EGF and bFGF alone were ineffective in growth stimulation (Figure 4A, red bars). Supplementation with NECA in addition to EGF and bFGF enabled us to maintain these spheroid lines stably. Accordingly, we were able to infect them with a lentivirus, and make them express the luciferase gene. By luciferase assays, we confirmed that addition of three supplementary factors stimulated their growths by $>50 \%$ (Figure $6 \mathrm{~F}$ ). The increments of GEI were critical for their propagation because they barely grew in the cancer medium alone (growth rates, $\sim 1.0$ ) (Supplementary Figure 3E). These results suggest that activation of the cAMP-PKA and mitogen-activated protein kinases (MAPK)/extracellular signal-regulated kinases (ERK) signaling enhances proliferation of CRC-TIC spheroids in an additive manner though not synergistic. Thus, we can cultivate even some extremely slow-growing spheroids by supplementing the basal cancer medium with three additional ingredients, EGF, bFGF, and NECA.

\section{Optimized culture conditions for the patient- derived spheroids}

On the basis of the above results, we modified our previous culture media for both normal and cancer SC spheroids. A ROCK inhibitor, Y27632, is required to maintain human colorectal cancer stem cells [26, 27], as well as human gastrointestinal stem cells [15]. We found that Y27632 also increased the growths of CRC spheroids ( 6 of 12 lines tested) at a dose of $10 \mu \mathrm{M}$ (Supplementary Figure 4A). A TGF- $\beta$ type I receptor inhibitor, SB431542, is essential for long-term culture of human normal
A

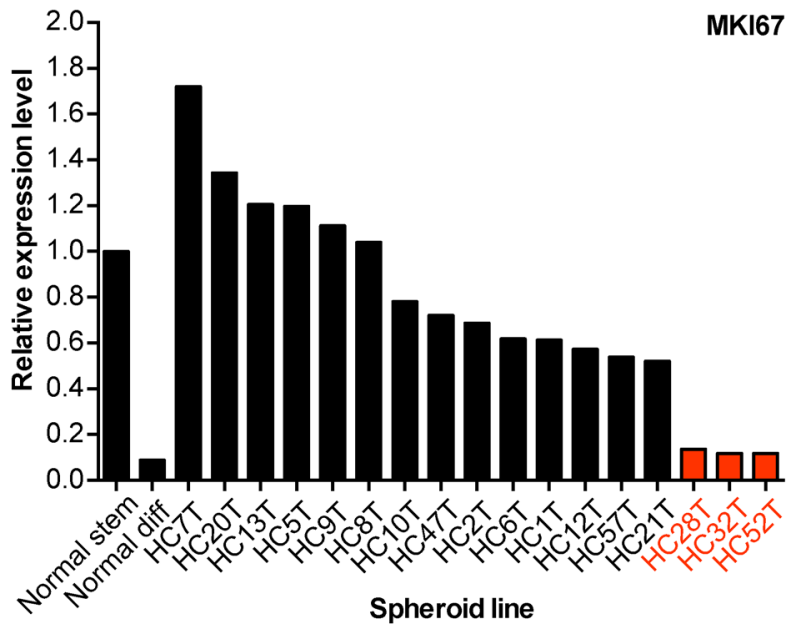

B

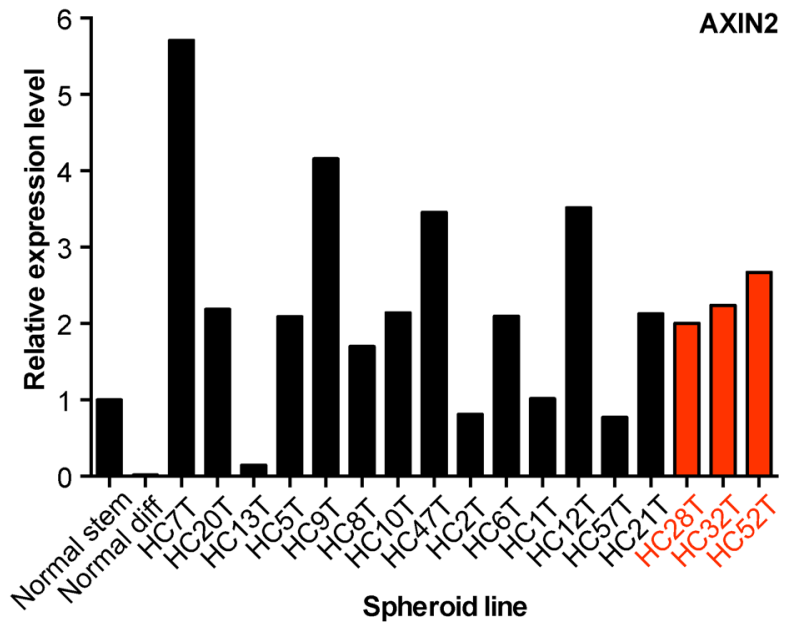

Figure 4: Ligand-independent Wnt-signaling activation in CRC-TIC spheroid lines. (A, B) Expression levels of MKI67 (Ki-67) (A) and AXIN2 (B) mRNAs. Normal colonic epithelial SC spheroids were cultured in the eL-WRN medium (Normal stem) or the differentiation medium (Normal diff), whereas CRC-TIC spheroids were cultured in the cancer medium supplemented with EGF and bFGF. Shown are the mean expression levels in triplicates relative to those in normal colonic epithelial SCs (Normal stem). Data of three slowgrowing CRC-TIC lines are presented in red. 


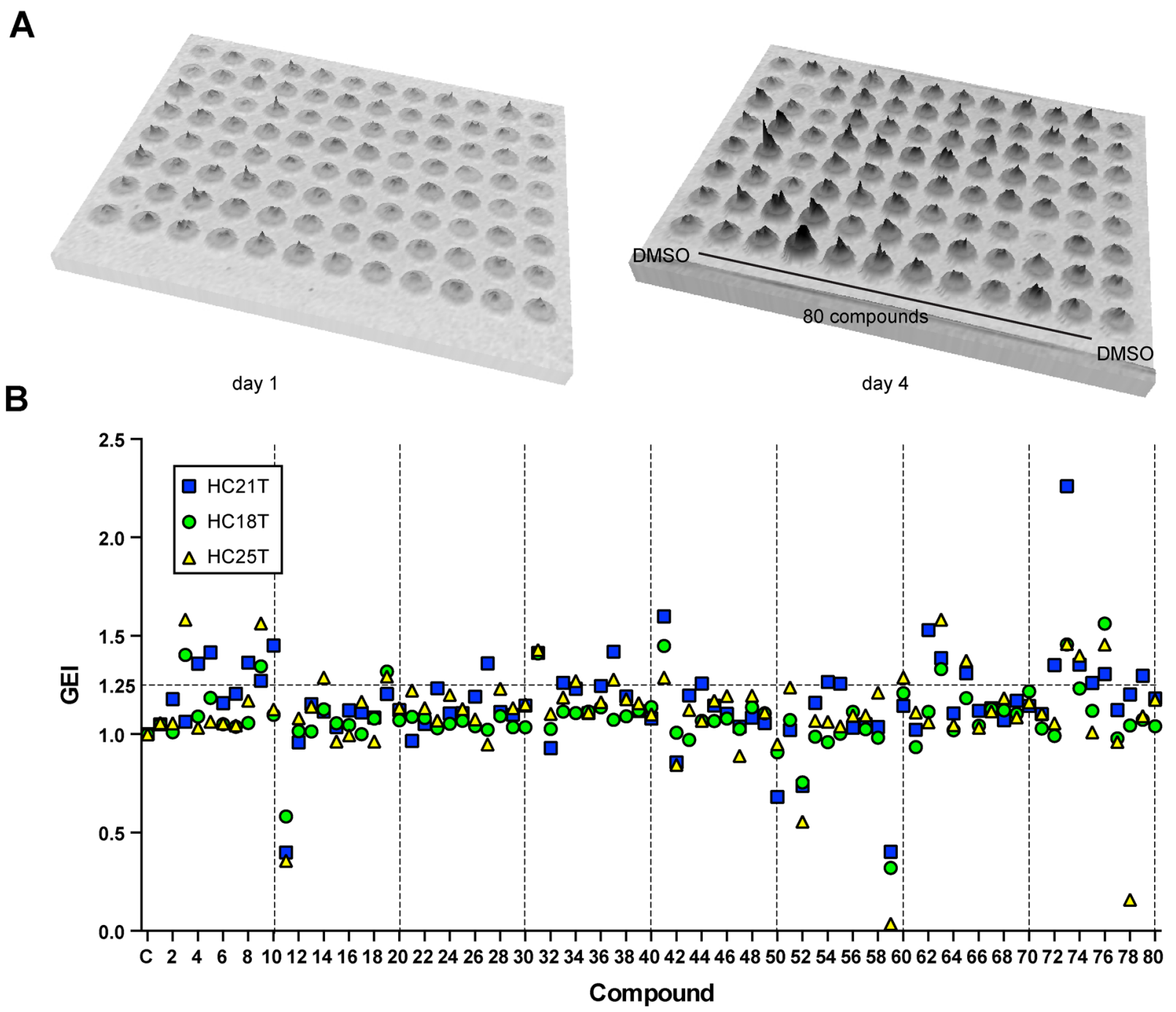

\begin{tabular}{|c|c|c|c|}
\hline 1 Isoproterenol hydrochloride & 21 Pindolol & 41 SKA 31 & $61(-)$-Quinpirole hydrochloride \\
\hline 2 L-Cysteinesulfinic acid & 22 Clofibric acid & 42 Cisapride & 62 Formoterol hemifumarate \\
\hline 3 L- 165,041 & 23 5-Methylfurmethiodide & 43 Cirazoline hydrochloride & $63 S 26948$ \\
\hline 4 THIP hydrochloride & 24 Cisplatin & 44 Rilmenidine hemifuramate & 64 PRE-084 hydrochloride \\
\hline 5 WAY 200070 & 25 Spaglumic acid & 45 Muscimol & 65 NMDA \\
\hline 65 -lodo-A-85380 dihydrochloride & $26 \mathrm{~m}$-Chlorophenylbiguanide hydrochloride & 46 Quinolinic acid & 66 Lobeline hydrochloride \\
\hline 7 Eletriptan hydrobromide & 27 Buspirone hydrochloride & $47(-)-U-50488$ hydrochloride & 67 Pilocarpine hydrochloride \\
\hline 8 Dimaprit dihydrochloride & 28 ATPA & 481 -EBIO & $68(E)$-Capsaicin \\
\hline 9 GW 7647 & 29 RWJ 21757 & 49 (RS)-AMPA hydrobromide & 69 BRL 37344 , sodium salt \\
\hline 10 Procaterol hydrochloride & 30 Histamine dihydrochloride & 50 TTNPB & 70 ZD 7114 hydrochloride \\
\hline 11 GW 3965 hydrochloride & $31 \mathrm{CV} 1808$ & 51 WY 14643 & 71 ABT 724 trihydrochloride \\
\hline 12 WAY 161503 hydrochloride & 32 (R)-(-)-Apomorphine hydrochloride & $52 \mathrm{~T} 0901317$ & 72 L-Quisqualic acid \\
\hline 13 A 61603 hydrobromide & 33 (士)-Bay K 8644 & 53 Ibotenic acid & 73 NECA \\
\hline 14 SR 11237 & 34 Dobutamine hydrochloride & 54 UK 14,304 tartrate & 74 Immepip dihydrobromide \\
\hline 15 BW 723C86 hydrochloride & 35 Melatonin & 55 SKF 77434 hydrobromide & 75 Amthamine dihydrobromide \\
\hline 16 a-Methyl-5-hydroxytryptamine maleate & $36 \mathrm{~N}$ a-Methylhistamine dihydrochloride & 56 PSN 375963 hydrochloride & 76 GW 0742 \\
\hline 17 CITCO & 37 DCEBIO & 57 5-Carboxamidotryptamine maleate & 77 Guanabenz acetate \\
\hline $18 \mathrm{AM} 580$ & 38 Oleamide & $58 \mathrm{~m}-3 \mathrm{M} 3 \mathrm{FBS}$ & $78 \mathrm{GW} 405833$ \\
\hline 19 AC 55649 & 39 FPL 64176 & $59 \mathrm{CD} 437$ & 79 Ceramide \\
\hline 20 PNU 282987 & 40 Spermidine trihydrochloride & 60 CP 93129 dihydrochloride & 80 Olvanil \\
\hline
\end{tabular}

Figure 5: Screening for growth-stimulating compounds on CRC-TIC spheroids. (A) Computerized presentation of bioluminescence from a luciferase-expressing CRC-TIC spheroid line (HC21T) upon incubation with the test compounds separately at $10 \mu \mathrm{M}$ each. Bioluminescence was detected before (day 1, left) and after (day 4, right) the drug treatment. The summit in each well represents direct photon counts for the spheroids embedded in each Matrigel drop. (B) Effects of eighty compounds on the growths of three CRC-TIC spheroid lines. Shown are the GEI in three independent spheroid lines (top) and the list of compounds (bottom). 
A
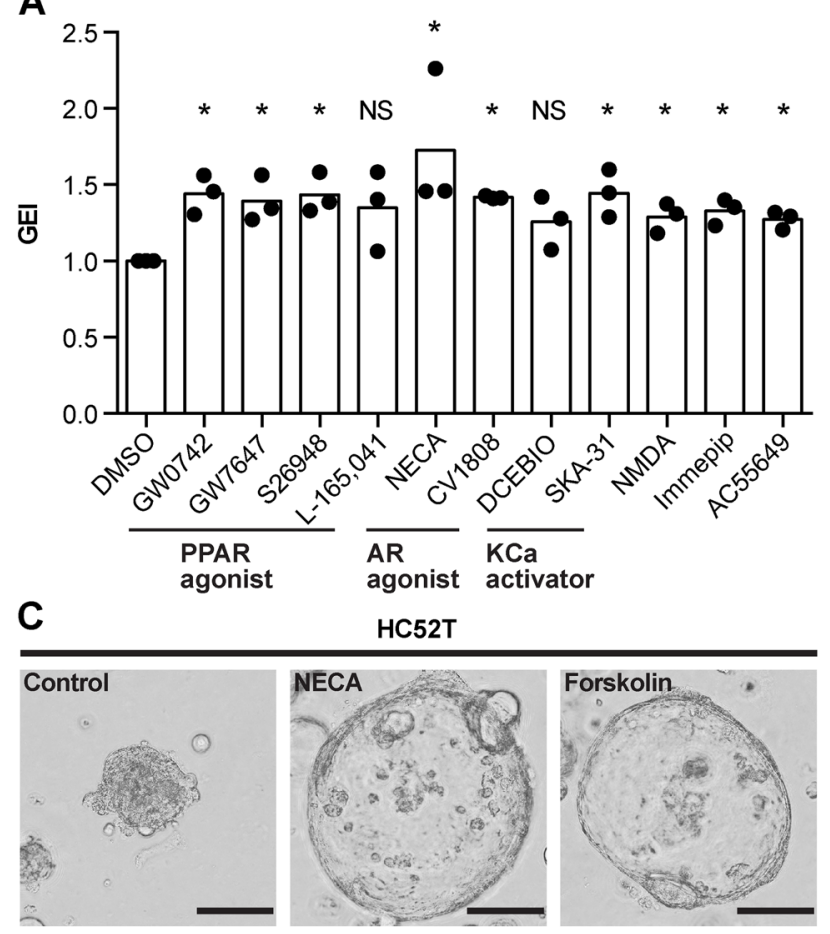

$\mathbf{F}$
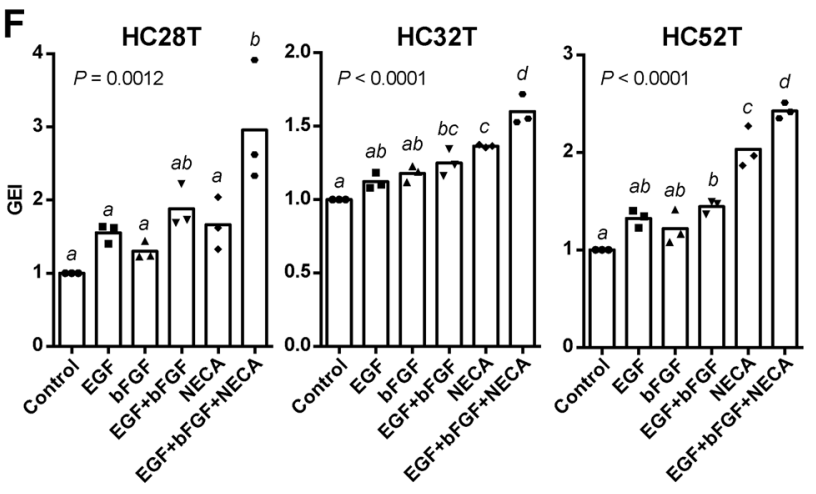

B
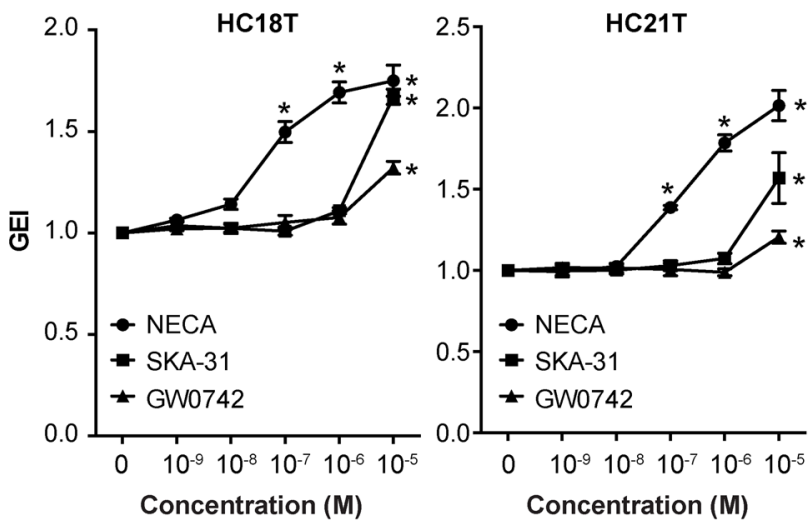

E

D
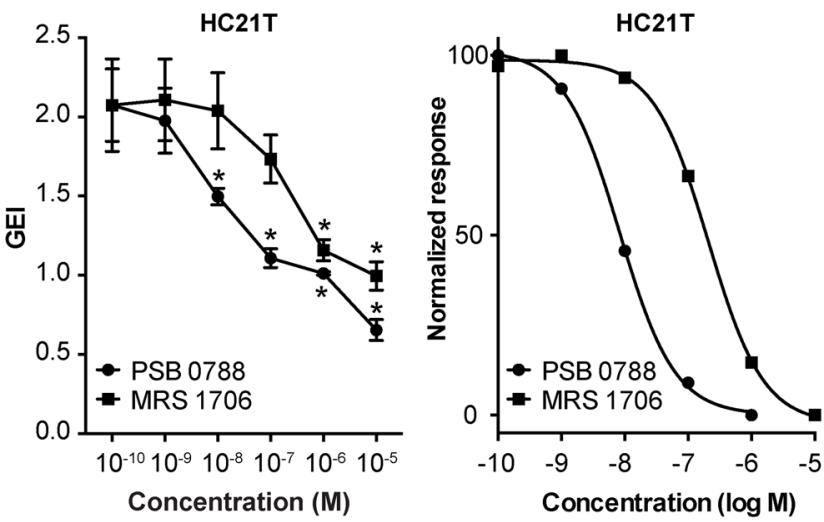

Figure 6: Evaluation of chemical compounds that facilitate the growth of CRC-TIC spheroids. (A) Growth-promoting effects of the compounds identified in Figure 5B. Shown are the data sets with mean values $>1.25$ (i.e., $>25 \%$ increase in growth). More than one compounds in each of three groups showed growth stimulation: peroxisome proliferator-activated receptor agonist (PPAR agonist); adenosine receptor agonist (AR agonist); calcium-activated potassium channel activator (KCa activator). Plotted are the GEI with means in three independent spheroid lines. Asterisks indicate statistically significant differences from the solvent-only $(0 \mu \mathrm{M})$ spheroids ( $P<0.05$; analyzed using Student's $t$-test). ND, no significant difference. (B) Dose-dependent effects of the selected three compounds on the growths of two colorectal cancer spheroid lines (HC18T and HC21T). Shown are the mean GEI \pm SD in three independent experiments. Asterisks indicate statistically significant differences from the solvent-only $(0 \mu \mathrm{M})$ spheroids $(P<0.05$; analyzed using one-way ANOVA followed by Tukey's post-test). (C) Representative phase-contrast micrographs of spheroids after NECA or forskolin treatment. Colorectal cancer spheroids (HC52T) were cultured with solvent only, $1 \mu \mathrm{M} \mathrm{NECA}$, or $1 \mu \mathrm{M}$ forskolin for five days. Note the increased sizes of NECA- and forskolin-treated spheroids caused by cell flattening. Scale bar, $100 \mu \mathrm{m}$. (D, E) Dose-dependent inhibitory effects of adenosine receptor antagonists (PSC 0788 and MRS 1706) on the growth of CRC-TIC spheroids (HC21T) cultured in the presence of $1 \mu \mathrm{M}$ NECA. Shown are the mean GEI \pm SD (D) and fitted curves of the normalized mean values (E) in three independent experiments. Asterisks in (D) indicate statistically significant differences from the solvent-only $(0 \mu \mathrm{M})$ spheroids $(P<0.05$; analyzed using one-way ANOVA followed by Tukey's post-test). (F) Growth stimulation by three supplementary factors on slow-growing spheroid lines. Luciferase-expressing spheroids were cultured in the presence of the indicated factor(s) for 3 days. Plotted are the GEI with means in three independent experiments calculated from the same data sets in Supplementary Figure 3E. Data were analyzed using one-way ANOVA ( $P$ values are shown in the graphs) followed by Tukey's post-test. The mean values between the different letters are statistically different $(P<0.05)$. 
gastrointestinal spheroids [15]. On the other hand, SB431542 supported the growths of some CRC spheroid lines (3 of 10 lines tested) although its effects were not as dramatic as that on normal colonic spheroids (Figure 7A, 7B, and Supplementary Figure 4B). We optimized its concentration to $1 \mu \mathrm{M}$ to avoid its growth inhibition often observed at $10 \mu \mathrm{M}$ (Figure 7A and Supplementary Figure 4B). To the eL-WRN medium for the normal epithelial SC spheroids, we added EGF because it often promoted their growth, too (Figure 3D). In addition, NECA and the B27 supplement, a cocktail of antioxidants, supported establishment of spheroid lines that grew poorly in early passages (Figure 7C). Therefore, we recommend including EGF, bFGF, NECA, and the B27 supplement in the initial culture of PD-CRC-TICs, and determining later whether these growth factors are essential to maintain them. Owing to these optimizations, our success rate for establishing CRC-TIC spheroids increased to $\sim 90 \%$ during the latest quarter (Table 1). A schematic workflow is summarized in Figure 8A and 8B for culturing CRC-TIC spheroids and normal colonic epithelial SC spheroids.

\section{DISCUSSION}

In the present study, we developed an improved method for establishing human CRC-TIC spheroids, using a simple culture medium with minimal supplementary factors. Namely, our basal cancer medium consisted of "Advanced DMEM/F12" supplemented with Y27632, SB431542, and FBS. The ROCK inhibitor, Y27632, was reported to inhibit anoikis of dissociated human embryonic stem cells [28], and has been used for culturing normal human intestinal organoids/spheroids $[15,29]$. The TGF- $\beta$ type I receptor inhibitor, SB431542, appears to help CRC-cell proliferation that can be inhibited by TGF- $\beta$ signaling $[30,31]$. Supplementation with these two inhibitors supported the growth of mouse intestinal adenoma spheroids in the same serum-containing medium $[14,32]$, hence the present application to human CRC-TIC cells as well.

Although the cancer medium enabled us to culture $>70 \%$ of the colorectal cancer samples into TIC spheroids, not all of them were successful. Poor spheroid growth in early passages was the commonest cause of unsuccessful culture. One of the conceivable reasons is that the resected tissue samples contained few TICs. Such tissue pieces may be composed mostly of normal epithelial cells, stromal cells, or differentiated cancer cells such as mature goblet cells in case of low-grade adenocarcinoma (Figure 1). To avoid this problem, we recommend collecting more than one tissue samples from different regions of a tumor (Figure 8A). Another conceivable reason is lack of the

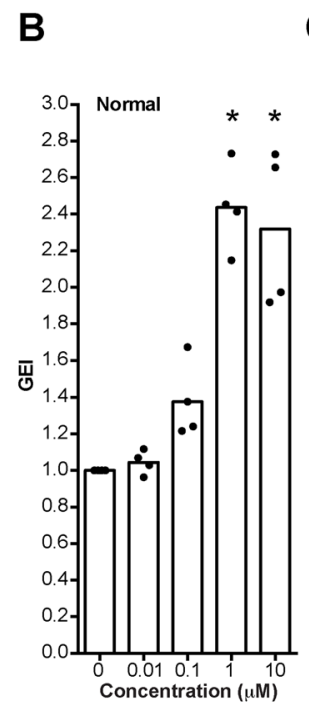

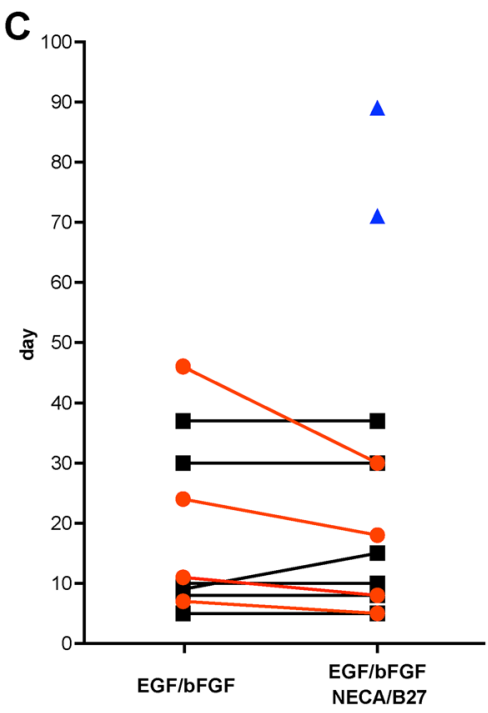

Figure 7: Optimization of spheroid culture conditions. (A, B) Dose-dependent effects of SB431542 on the growths of cancer (A) and normal (B) spheroid lines. Luciferase-expressing cancer and normal spheroids were cultured in the EGF/bFGF-containing cancer medium and the eL-WRN medium, respectively, in the presence of SB431542 at the indicated concentrations. Plotted are the GEI with means in three independent experiments (A) or those in four independent spheroid lines (B). Asterisks indicate statistically significant differences from the solvent-only $(0 \mu \mathrm{M})$ spheroids $(P<0.05$; analyzed using one-way ANOVA followed by Tukey's post-test). Note that the effects on cancer spheroids are less than those on normal spheroids. (C) Growth-supportive effects of NECA and the B27 supplement for culture initiation of colorectal cancer tissues. Epithelial cells separated from colorectal cancer tissues were cultured with the EGF/bFGFcontaining cancer medium in presence or absence of NECA and the B27 supplement. Plotted are times needed for expansion of spheroids to four wells of a 12-well cell-culture plate. Of eleven cases tested, supplementation of NECA/B27 was essential to establish spheroid lines in two cases (blue triangles), promoted faster spheroid growth in four cases (red circles), and showed no supportive effect in other five cases (black squares). 
critical factor(s) that supports adaptation of colorectal cancer cells to the in vitro culture microenvironment. To address this issue, we searched for additional supplementary factors that increased the efficiency in establishing CRC-TIC spheroid lines. To this end, we developed an accurate but simple growth-monitoring method for 3D-cultured spheroids; employment of GEI based on luciferase bioluminescence.

Two signaling pathways play central roles in intestinal epithelial cell growth in vitro; namely, those
A

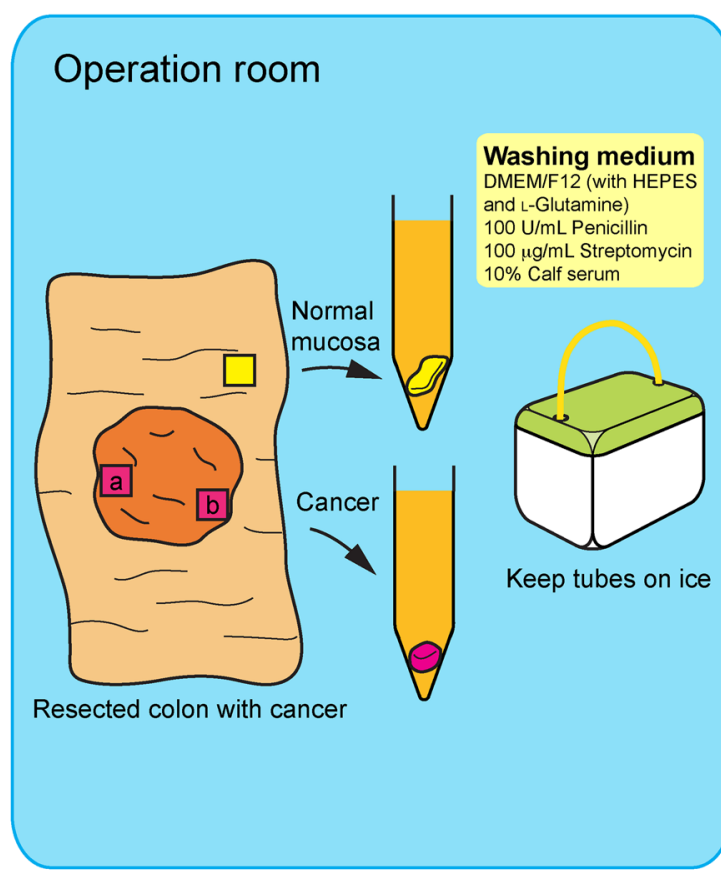

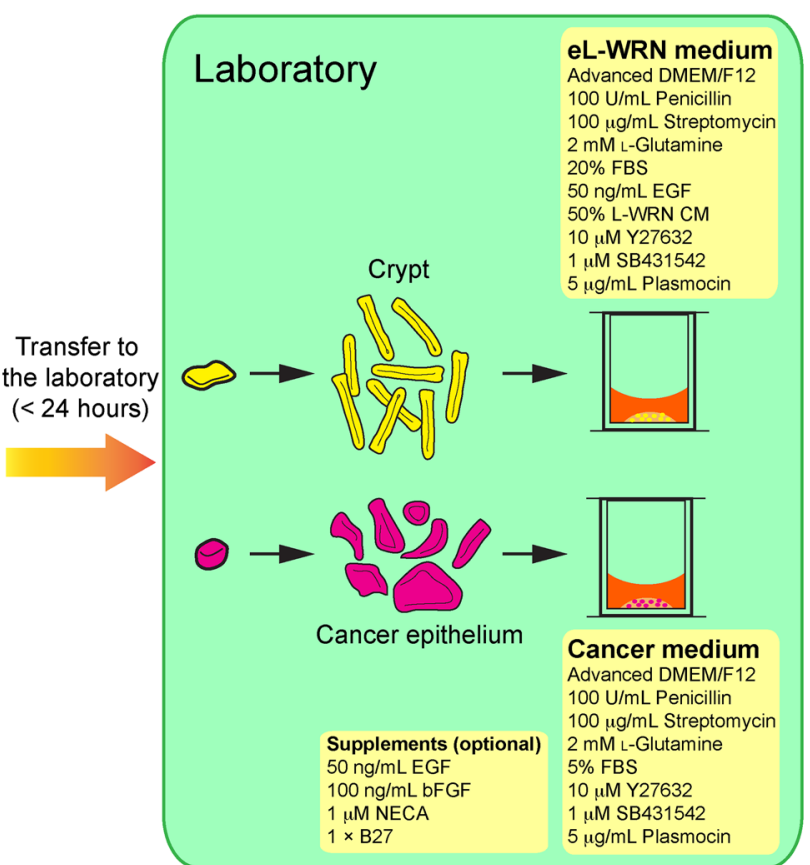

B

\section{Cancer spheroids}

Primary culture $(\mathrm{PO})$

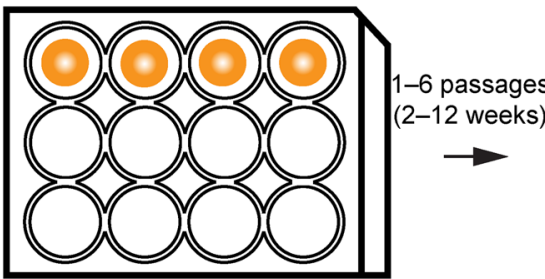

2-8 wells

\section{Normal epithelial spheroids}

Primary culture (PO)

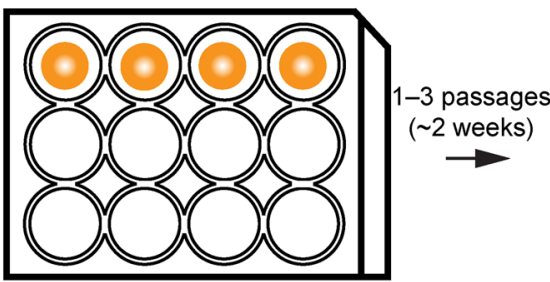

2-8 wells
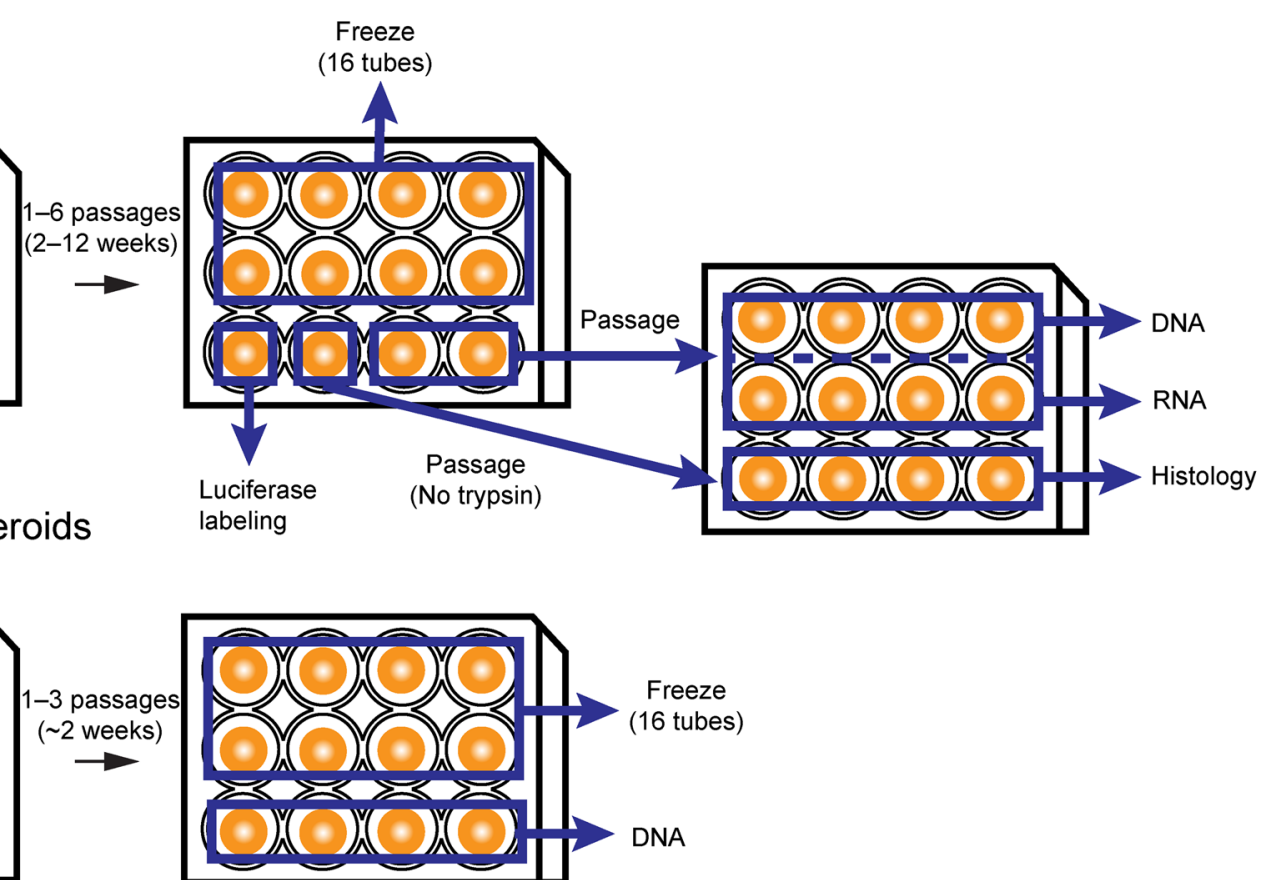

Figure 8: A schematic workflow for establishing patient-derived CRC-TIC spheroids. (A) The outline of procedures in the operation room and laboratory. We recommend collecting tumor samples from at least two different tumor regions (a and b). (B) Details for the spheroid propagation and sample preparation processes. For preparation of histological specimens, spheroids should be passaged without trypsinization so that large aggregates are formed (see Figure 1). 
of the canonical Wnt signaling and MAPK/ERK [33]. Although a recent study reported that a subpopulation of colorectal cancer organoids was dependent on Wnt ligands for their growth [11], our attempts to culture CRC-TIC spheroids in the Wnt-containing L-WRN medium resulted in predominant propagation of the normal epithelial cells that remained in the tumor tissue. On the other hand, we found that EGF and bFGF effectively enhanced the growth of CRC-TIC spheroids carrying wild-type $R A S / R A F$ genes. Interestingly, we identified multiple colorectal cancer spheroid lines that depended on bFGF for their growth rather than on EGF (Figure 3B), suggesting that FGFR inhibitors may suppress the growth of CRC-TICs, through blocking the Ras/Raf/ERK pathway [34]. Consistently, a recent study showed that $F G F 9$ gene amplification was associated with resistance of colorectal cancer cells to cetuximab [20]. Notably, at least two of our spheroid lines (HC6T and HC9T) that responded well to bFGF contained such gains of its chromosomal region (Figure 3E). Thus, the combination of an FGFR inhibitor and cetuximab can be more efficacious in treating colorectal cancer with wild-type $R A S / R A F$ genes. Our method should help screen patients suitable for such a therapy.

In addition, we found that NECA, an adenosine receptor agonist, accelerated growth of some slowgrowing spheroids (Figure 6D). The characteristic changes in the spheroid morphology by adenosine receptor agonists strongly suggest involvement of the cAMP-PKA pathway [25]. Activation of cAMP-PKA signaling induces metabolic changes that confer resistance to glucose deprivation and anoikis on cancer cells [35, 36]. Consistently, we noticed that supplementation with NECA was effective in case spheroid cells grew poorly in early passages (Figure 7C), suggesting the role of NECA in CRC-TIC adaptation to in vitro culture. Because $\mathrm{A}_{2 \mathrm{~B}}$ antagonists canceled the growth-promoting effect of NECA (Figure 6D, 6E), and can inhibit the growth of prostate cancer and colonic adenocarcinoma cells [37, 38], the adenosine receptor inhibitor may be one of promising candidates in cancer therapy.

In conclusion, we developed an efficient and lowcost propagation method for CRC-TIC spheroids. With the optimized culture protocols, our success rate for establishing colorectal cancer spheroids has increased to $\sim 90 \%$ (Table 1). Accordingly, it has become a practical and feasible strategy to exploit PD-CRC-TICs for clinical applications. Cultured spheroids consist of the pure cancer cell population without stromal cells, which provides an excellent source for high-quality DNA samples that enable unambiguous genetic diagnosis. Accurate mutational profiles of the primary CRC-TICs should help determine the chemotherapeutics more efficiently. When treatments with the current regimen fail, patient-derived "spheroid" xenografts (PDSX) may provide sensitivity tests for other available or novel therapeutic regimens. Compared with transplantation of the whole patient tumor tissues, that of CRC-TIC spheroids should provide test mice more suitable for precise evaluation of drug sensitivity personalized for each patient.

\section{MATERIALS AND METHODS}

\section{Reagents and antibodies}

The following reagents were purchased from commercial sources: luciferin (Promega, Madison, WI, USA), a chemical collection for agonists/activators (S990043-AGO1), 5'-(N-ethyl-carboxamido)-adenosine (NECA), 2-phenylaminoadenosine (CV1808), SKA-31 (Sigma, St. Louis, MO), Y27632, SB431542, GW0742, PSB 0788, MRS 1706 (R\&D Systems, Minneapolis, $\mathrm{MN})$. The L-WRN cells [13] were obtained from Dr. Thaddeus S. Stappenbeck (Washington University), and their conditioned medium (L-WRN CM) was prepared according to a reported protocol [14].

\section{Human samples}

Tumor samples were obtained from a total of 141 colorectal cancer patients who underwent primary resections at Kyoto University Hospital (KUHP) between October 2014 and March 2017. Their diagnosis was confirmed as colorectal cancer through histopathologic examinations by board-certified pathologists at KUHP. The study protocols were approved by the institutional review board of KUHP, and patients provided written consents for investigational analyses.

\section{Initial spheroid culture of human CRC-TICs and normal colonic epithelial cells}

From each surgical specimen that contained the colorectal cancer lesion(s) and surrounding tissues, $\sim 2$ pieces of the tumor $\left(0.5-4 \mathrm{~cm}^{3}\right.$ each) and one piece of normal mucosa $\left(\sim 4 \mathrm{~cm}^{2}\right)$ were isolated, and transferred to the laboratory in the ice-cold washing medium [DMEM/ F12 with HEPES and L-glutamine (Nacalai Tesque, Kyoto, Japan), 100 units/ml penicillin (Nacalai), $0.1 \mathrm{mg} /$ $\mathrm{ml}$ streptomycin (Nacalai), and $10 \%$ calf serum (Sigma)]. Tissues were processed within $24 \mathrm{~h}$ after surgery. A piece of the colorectal cancer specimen $\left(0.5-1.0 \mathrm{~cm}^{3}\right)$ or a flap of the normal mucosa $\left(1-2 \mathrm{~cm}^{2}\right)$ was separated from the connective tissue, washed with PBS, and minced using scissors in a $60-\mathrm{mm}$ petri dish. The tissue fragments were digested in $2 \mathrm{ml}$ of collagenase solution [the washing medium supplemented with $0.2 \%$ collagenase type I (Thermo Fisher Scientific, Waltham, MA) and $50 \mu \mathrm{g} / \mathrm{ml}$ gentamicin (Thermo Fisher)] at $37^{\circ} \mathrm{C}$ for $40-60 \mathrm{~min}$, and dissociated by pipetting with a $1 \mathrm{ml}$-pipette with $\sim 20 \mathrm{~min}$ intervals $2-3$ times. Then, epithelial cell clusters were filtered through a $100-\mu \mathrm{m}$ cell strainer (Corning Inc., Corning, NY), and collected according to a previous 
report [15]. Epithelial cells were then resuspended in Matrigel (Corning), and placed in the center of each well of the 12-well cell-culture plate $(30 \mu \mathrm{l}$ per well; TPP, Trasadingen, Switzerland). After polymerization of Matrigel at $37{ }^{\circ} \mathrm{C}$, epithelial cells were cultured with the cancer medium [Advanced DMEM/F-12 (Thermo Fisher), 100 units $/ \mathrm{ml}$ penicillin, $0.1 \mathrm{mg} / \mathrm{ml}$ streptomycin, $2 \mathrm{mM}$ L-glutamine, $10 \mu \mathrm{M}$ Y27632, 10 or $1 \mu \mathrm{M} \mathrm{SB} 431542,5 \mu \mathrm{g} / \mathrm{ml}$ Plasmocin (Invivogen, San Diego, CA), and 5\% FBS (Thermo Fisher)] or in the eL-WRN medium [Advanced DMEM/F-12, 100 units $/ \mathrm{ml}$ penicillin, $0.1 \mathrm{mg} / \mathrm{ml}$ streptomycin, $2 \mathrm{mM}$ L-glutamine, 50\% L-WRN CM, $10 \mu \mathrm{M}$ Y27632, 10 or $1 \mu \mathrm{M}$ SB431542, 50 ng/ml EGF (Peprotech, Rocky Hill, NJ), $5 \mu \mathrm{g} / \mathrm{ml}$ Plasmocin, and 20\% FBS]. When necessary, the cancer medium was supplemented with $100 \mathrm{ng} / \mathrm{ml}$ basic bFGF (Peprotech), $50 \mathrm{ng} / \mathrm{ml}$ EGF, $1 \mu \mathrm{M}$ NECA, and/or $1 \times$ B27 supplement (Thrmo Fisher) to support the growth of slow-growing spheroids. The differentiation medium for normal colonic epithelial spheroids were prepared as described previously [25]. The medium was changed every other day. Phase-contrast images of spheroids were captured through OLYMPUS IX70 microscope (OLYMPUS, Tokyo, Japan) equipped with OLYMPUS DP70 digital camera and DP Controller 1.2 software (OLYMPUS).

\section{Lentivirus infection of spheroids}

A cDNA fragment encoding a firefly luciferase (luc2, Promega) was inserted into the $\mathrm{pCX}$ vector that contained a CAG promoter [18] to construct pCX-Luc2. The expression unit (CAG-luciferase) of pCX-Luc2 was inserted into a lentiviral vector (pCDH, System Biosciences, Palo Alto, CA) to construct pCDH-CAGLuc2. Lentiviral particles were prepared according to a protocol with minor modifications [14]. Briefly, $2 \times 10^{7}$ of 293FT cells (Thermo Fisher) were seeded on four 10 cm-dishes, and cultured overnight. Cells were transfected with DNA of $40 \mu \mathrm{g}$ pCDH-CAG-Luc2 plasmid, $26 \mu \mathrm{g}$ psPAX2 packaging plasmid, and $14 \mu \mathrm{g}$ pMD2.G envelope plasmid, with the use of Lipofectamine 2000 (Thermo Fisher). Viral particles were harvested on the second and third days after transfection, and precipitated using PEGit Virus-Precipitation Solution (System Biosciences). Viral particles were resuspended in $2 \mathrm{ml}$ of the washing medium, aliquoted into forty $1.5 \mathrm{ml}$-tubes (50 $\mu \mathrm{l} \mathrm{each),}$ and stored at $-80^{\circ} \mathrm{C}$. Spheroids cultured in one well of a 12-well cell-culture plate were trypsinized, and about half of the cells were collected by centrifugation $(200 \times$ $g$ ) in a $1.5 \mathrm{ml}$-tube. Cells were resuspended in $50 \mu \mathrm{l}$ of the virus solution containing $10 \mu \mathrm{g} / \mathrm{ml}$ hexadimethrine bromide and $10 \mu \mathrm{M} \mathrm{Y} 27632$, and incubated at $37^{\circ} \mathrm{C}$ for $6 \mathrm{~h}$. Then, the cells were collected by centrifugation (200 $\times g$ ), resuspended in $60 \mu \mathrm{l}$ of Matrigel, and seeded into two wells of a 12-well cell-culture plate.

\section{Luminescence-based growth monitoring in spheroid culture}

For growth monitoring assays, luciferase-expressing spheroids were cultured in 2-3 wells of a 12-well cellculture plate. Spheroids were trypsinized, filtered through a 40- $\mu \mathrm{m}$ cell strainer (Corning), and resuspended in 300 $\mu 1$ of Matrigel for a 96-well plate. Dilution (based on the volume of Matrigel) was adjusted 4-8 times depending on the growth rate and spheroid density. The spheroid cells in Matrigel were distributed to the wells of 96-well "white" cell-culture plates (Corning; $3 \mu$ l per well) on a plate heater at $37^{\circ} \mathrm{C}$, and cultured overnight in $100 \mu \mathrm{l} /$ well of the medium. Spheroids were rinsed with $100 \mu \mathrm{l} /$ well of PBS, and incubated with $50 \mu \mathrm{l} /$ well of $150 \mu \mathrm{g} /$ $\mathrm{ml}$ luciferin in the phenol red-free DMEM/F12 medium (Nacalai) at room temperature $\left(20-28{ }^{\circ} \mathrm{C}\right)$ for $10 \mathrm{~min}$. Luminescence was scored using a conventional imaging device (Gel Doc XR+, BioRad, Hercules, CA). After this initial measurement, spheroids in each well were rinsed with $100 \mu \mathrm{l}$ of PBS, and cultured in $100 \mu \mathrm{l}$ of the selected medium. Luminescence was determined daily or 3 days later. The cell growth rate for each well was estimated as the proportion of photon counts to those on the initial measurement. In Y27632 treatment experiments, the initial and second measurements were performed on post-passage days 0 and 2, respectively. Three to six replicates were analyzed for each data point in all experiments except for the chemical compound screening assays (resulted in similar statistical power).

\section{Preparation of RNA from spheroids}

After aspiration of the medium, the lysis buffer (Takara Bio Inc., Kusatsu, Japan) was directly added to each well of spheroid culture. RNA was purified using NucleoSpin RNA II kit (Takara).

\section{Quantitative RT-PCR (qRT-PCR)}

Molecules of cDNA were synthesized using SuperScript III (Thermo Fisher), and qPCRs were performed using SYBR Green reagents (Toyobo, Osaka, Japan) in an ABI StepOnePlus thermal cycler (Thermo Fisher). Expression levels were normalized relative to those of $A C T B$. Sequences of primer pairs were as follows: AXIN2, CATGACGGACAGCAGTGTAGA and AACTCCAGCTTCAGCTTTTCC; MKI67, AAGAGA GTGTCTATCAGCCGAAGT and GTGGCCTGTACT AAATTGACTGTG; $A C T B$, CATGTACGTTGCTAT CCAGGC and CTCCTTAATGTCACGCACGAT.

\section{Preparation of DNA and histology specimens from spheroids}

Spheroids in Matrigel were suspended in Cell Recovery Solution (Corning), and collected in $1.5 \mathrm{ml}-$ 
tubes. Matrigel was digested at $4{ }^{\circ} \mathrm{C}$ with rotation for 30-60 min. Spheroids were centrifuged at $200 \times g$ for $5 \mathrm{~min}$, and washed with PBS twice at $4{ }^{\circ} \mathrm{C}$. DNA was purified using DNeasy Blood \& Tissue Kit (Qiagen, Hilden, Germany). For histological analyses, spheroids were passaged once or twice without trypsinization so that larger cell aggregates were formed. They were embedded in iPGell (Genostaff, Tokyo, Japan), and fixed with 4\% paraformaldehyde in $\mathrm{PBS}$ at $4^{\circ} \mathrm{C}$ for $16 \mathrm{~h}$.

\section{Histopathological classification of colorectal cancer}

Formalin-fixed paraffin-embedded specimens were sectioned at 4- $\mu \mathrm{m}$ thickness, and stained with H\&E. Histological images were captured through Leica DM2000 microscope (Leica Microsystems, Wetzlar, Germany) equipped with OLYMPUS DP73 digital camera and cellSens Standard 1.6 software (OLYMPUS). Histological grades of primary cancer and spheroids were determined according to the WHO guideline and the recommendation of the College of American Pathologists [16, 17].

\section{Mutational hotspot analysis}

Hotspot mutations in 50 cancer-related genes were detected by Macrogen (Seoul, Republic of Korea) using Ion AmpliSeq Cancer Hotspot Panel v2 (Thermo Fisher). The list of sequenced genes and mutations is available from manufacturer's website (http://tools.invitrogen.com/ downloads/cms_106003.csv). The data sets were analyzed using Integrative Genomics Viewer software (Broad Institute).

\section{Array-based comparative genomic hybridization (CGH) analysis}

Array-based $\mathrm{CGH}$ analyses were performed with Agilent SurePrint G3 human CGH microarray $1 \times 1 \mathrm{M}$ (G4447A, Agilent, Santa Clara, CA) and Genomic DNA ULS Labeling Kit (\#5190-0419, Agilent) according to the manufacturer's instructions. Human Genomic DNA (G1521 and G1471, Promega) was used as the control. The array slides were scanned using Agilent G2565BA microarray scanner (Agilent) at the Medical Research Support Center, Graduate School of Medicine, Kyoto University.

\section{Statistical tests}

All statistical analyses were performed using GraphPad PRISM software version 6 (GraphPad Software, La Jolla, CA).

\section{Dose-response curve}

The luminescence signal intensities were normalized and fitted to the dose-response model using PRISM version 6 .

\section{Abbreviations}

Patient-derived colorectal cancer (PD-CRC), tumor initiating cell (TIC), epidermal growth factor (EGF), basic fibroblast growth factor (bFGF), 5'-( $N$-ethylcarboxamido)-adenosine (NECA), epidermal growth factor receptor (EGFR), vascular endothelial growth factor (VEGF), patient-derived xenograft (PDX), Rho-associated coiled-coil protein kinase (ROCK), transforming growth factor $\beta$ (TGF- $\beta$ ), stem cell (SC), growth effect index (GEI), peroxisome proliferator-activated receptor (PPAR), adenosine receptor (AR), calcium-activated potassiumchannel (KCa), cyclic AMP (cAMP), protein kinase A (PKA), mitogen-activated protein kinases (MAPK), extracellular signal-regulated kinases (ERK), patientderived spheroid xenografts (PDSX).

\section{Author contributions}

H Miyoshi and MM Taketo designed the research. H Miyoshi developed the methodology. H Miyoshi, H Maekawa, F Kakizaki, and T Yamaura performed experiments. H Miyoshi, H Maekawa, and F Kakizaki analyzed data. K Kawada and Y Sakai provided the materials. H Miyoshi, K Kawada, Y Sakai, and MM Taketo wrote the manuscript.

\section{ACKNOWLEDGMENTS}

We thank Dr. Thaddeus Stappenbeck, Department of Pathology and Immunology, Washington University School of Medicine, for comments on the manuscript. We thank the Medical Research Support Center, Graduate School of Medicine, Kyoto University for the technical supports. We also thank the members of the Division of Gastrointestinal Surgery, Department of Surgery, Kyoto University Hospital, for help in collection of surgical specimens. We are grateful to Drs. Takaki Sakurai and Hironori Haga, Department of Clinical Pathology, Kyoto University Hospital, for their pathological diagnosis.

\section{CONFLICTS OF INTEREST}

The authors declare no potential conflicts of interest.

\section{FUNDING}

This work was supported by Program for Creating STart-ups from Advanced Research and Technology (START; ST261001TT) from Japan Science and Technology Agency; Practical Research for Innovative Cancer Control (ck0106195h) from Japan Agency for Medical Research and Development; and Kyoto University Venture Incubation from Kyoto University Office of Society-Academia Collaboration for Innovation (all to M.M.T.). 


\section{REFERENCES}

1. Torre LA, Bray F, Siegel RL, Ferlay J, Lortet-Tieulent J, Jemal A. Global cancer statistics, 2012. CA Cancer J Clin. 2015; 65:87-108. https://doi.org/10.3322/caac.21262.

2. Kohne $\mathrm{CH}$. Successes and limitations of targeted cancer therapy in colon cancer. Prog Tumor Res. 2014; 41:36-50. https://doi.org/10.1159/000356436.

3. Cancer Genome Atlas N. Comprehensive molecular characterization of human colon and rectal cancer. Cancer Genome Atlas Network. 2012; 487:330-7. https://doi. org/10.1038/nature11252.

4. Carethers JM, Jung BH. Genetics and genetic biomarkers in sporadic colorectal cancer. Gastroenterology. 2015; 149:117790.e3. https://doi.org/10.1053/j.gastro.2015.06.047.

5. Wood LD, Parsons DW, Jones S, Lin J, Sjoblom T, Leary RJ, Shen D, Boca SM, Barber T, Ptak J, Silliman N, Szabo $\mathrm{S}$, Dezso Z, et al. The genomic landscapes of human breast and colorectal cancers. Science. 2007; 318:1108-13. https:// doi.org/10.1126/science. 1145720 .

6. Tentler JJ, Tan AC, Weekes CD, Jimeno A, Leong S, Pitts TM, Arcaroli JJ, Messersmith WA, Eckhardt SG. Patientderived tumour xenografts as models for oncology drug development. Nat Rev Clin Oncol. 2012; 9:338-50. https:// doi.org/10.1038/nrclinonc.2012.61.

7. Hidalgo M, Amant F, Biankin AV, Budinska E, Byrne AT, Caldas C, Clarke RB, de Jong S, Jonkers J, Maelandsmo GM, Roman-Roman S, Seoane J, Trusolino L, et al. Patient-derived xenograft models: an emerging platform for translational cancer research. Cancer Discov. 2014; 4:9981013. https://doi.org/10.1158/2159-8290.CD-14-0001.

8. Morton CL, Houghton PJ. Establishment of human tumor xenografts in immunodeficient mice. Nat Protoc. 2007; 2:247-50. https://doi.org/10.1038/nprot.2007.25.

9. Kondo J, Endo H, Okuyama H, Ishikawa O, Iishi H, Tsujii M, Ohue M, Inoue M. Retaining cell-cell contact enables preparation and culture of spheroids composed of pure primary cancer cells from colorectal cancer. Proc Natl Acad Sci U S A. 2011; 108:6235-40. https://doi.org/10.1073/ pnas. 1015938108.

10. van de Wetering M, Francies HE, Francis JM, Bounova G, Iorio F, Pronk A, van Houdt W, van Gorp J, Taylor-Weiner A, Kester L, McLaren-Douglas A, Blokker J, Jaksani S, et al. Prospective derivation of a living organoid biobank of colorectal cancer patients. Cell. 2015; 161:933-45. https:// doi.org/10.1016/j.cell.2015.03.053.

11. Fujii M, Shimokawa M, Date S, Takano A, Matano M, Nanki K, Ohta Y, Toshimitsu K, Nakazato Y, Kawasaki K, Uraoka T, Watanabe T, Kanai T, et al. A colorectal tumor organoid library demonstrates progressive loss of niche factor requirements during tumorigenesis. Cell Stem Cell. 2016; 18:827-38. https://doi.org/10.1016/j. stem.2016.04.003.
12. Pauli C, Hopkins BD, Prandi D, Shaw R, Fedrizzi T, Sboner A, Sailer V, Augello M, Puca L, Rosati R, McNary TJ, Churakova $\mathrm{Y}$, Cheung $\mathrm{C}$, et al. Personalized in vitro and in vivo cancer models to guide precision medicine. Cancer Discov. 2017; 7:462-77. https://doi.org/10.1158/2159-8290. CD-16-1154.

13. Miyoshi H, Ajima R, Luo CT, Yamaguchi TP, Stappenbeck TS. Wnt5a potentiates TGF- $\beta$ signaling to promote colonic crypt regeneration after tissue injury. Science. 2012; 338:108-13. https://doi.org/10.1126/science.1223821.

14. Miyoshi $\mathrm{H}$, Stappenbeck TS. In vitro expansion and genetic modification of gastrointestinal stem cells in spheroid culture. Nat Protoc. 2013; 8:2471-82. https://doi. org/10.1038/nprot.2013.153.

15. VanDussen KL, Marinshaw JM, Shaikh N, Miyoshi H, Moon C, Tarr PI, Ciorba MA, Stappenbeck TS. Development of an enhanced human gastrointestinal epithelial culture system to facilitate patient-based assays. Gut. 2015; 64:911-20. https://doi.org/10.1136/ gutjnl-2013-306651.

16. Hamilton SR, Aaltonen LA. Pathology and genetics of tumours of the digestive system: IARC press Lyon. 2000; 48:103-143.

17. Compton CC, Fielding LP, Burgart LJ, Conley B, Cooper HS, Hamilton SR, Hammond ME, Henson DE, Hutter RV, Nagle RB, Nielsen ML, Sargent DJ, Taylor CR, et al. Prognostic factors in colorectal cancer. College of american pathologists consensus statement 1999. Arch Pathol Lab Med. 2000; 124:979-94. https://doi. org/10.1043/0003-9985(2000)124<0979:PFICC>2.0.CO;2.

18. Niwa H, Yamamura K, Miyazaki J. Efficient selection for high-expression transfectants with a novel eukaryotic vector. Gene. 1991; 108:193-9. https://doi. org/10.1016/0378-1119(91)90434-D.

19. Barnes D, Sato G. Serum-free cell culture: a unifying approach. Cell. 1980; 22:649-55. https://doi. org/10.1016/0092-8674(80)90540-1.

20. Mizukami T, Togashi Y, Naruki S, Banno E, Terashima M, de Velasco MA, Sakai K, Yoneshige A, Hayashi H, Fujita Y, Tomida S, Nakajima TE, Fujino T, et al. Significance of FGF9 gene in resistance to anti-EGFR therapies targeting colorectal cancer: A subset of colorectal cancer patients with FGF9 upregulation may be resistant to anti-EGFR therapies. Mol Carcinog. 2017; 56:106-17. https://doi. org/10.1002/mc.22476.

21. van der Flier LG, Clevers H. Stem cells, self-renewal, and differentiation in the intestinal epithelium. Annu Rev Physiol. 2009; 71:241-60. https://doi.org/10.1146/annurev. physiol.010908.163145.

22. Lustig B, Jerchow B, Sachs M, Weiler S, Pietsch T, Karsten $\mathrm{U}$, van de Wetering M, Clevers H, Schlag PM, Birchmeier W, Behrens J. Negative feedback loop of Wnt signaling through upregulation of conductin/Axin2 in colorectal and liver tumors. Mol Cell Biol. 2002; 22:1184-93. https://doi. org/10.1128/mcb.22.4.1184-1193.2002. 
23. Jho EH, Zhang T, Domon C, Joo CK, Freund JN, Costantini $\mathrm{F}$. Wnt/beta-catenin/Tcf signaling induces the transcription of Axin2, a negative regulator of the signaling pathway. Mol Cell Biol. 2002; 22:1172-83. https://doi.org/10.1128/ MCB.22.4.1172-1183.2002.

24. Strohmeier GR, Reppert SM, Lencer WI, Madara JL. The A2b adenosine receptor mediates cAMP responses to adenosine receptor agonists in human intestinal epithelia. J Biol Chem. 1995; 270:2387-94. https://doi.org/10.1074/jbc.270.5.2387.

25. Miyoshi H, VanDussen KL, Malvin NP, Ryu SH, Wang Y, Sonnek NM, Lai CW, Stappenbeck TS. Prostaglandin E2 promotes intestinal repair through an adaptive cellular response of the epithelium. EMBO J. 2017; 36:5-24. https:// doi.org/10.15252/embj.201694660.

26. Wei L, Surma M, Shi S, Lambert-Cheatham N, Shi J. Novel insights into the roles of rho kinase in cancer. Arch Immunol Ther Exp (Warsz). 2016; 64:259-78. https://doi. org/10.1007/s00005-015-0382-6.

27. Ohata H, Ishiguro T, Aihara Y, Sato A, Sakai H, Sekine S, Taniguchi H, Akasu T, Fujita S, Nakagama H, Okamoto $\mathrm{K}$. Induction of the stem-like cell regulator CD44 by Rho kinase inhibition contributes to the maintenance of colon cancer-initiating cells. Cancer Res. 2012; 72:5101-10. https://doi.org/10.1158/0008-5472.CAN-11-3812.

28. Watanabe K, Ueno M, Kamiya D, Nishiyama A, Matsumura M, Wataya T, Takahashi JB, Nishikawa S, Nishikawa S, Muguruma K, Sasai Y. A ROCK inhibitor permits survival of dissociated human embryonic stem cells. Nat Biotechnol. 2007; 25:681-6. https://doi.org/10.1038/nbt1310.

29. Sato T, Stange DE, Ferrante M, Vries RG, Van Es JH, Van den Brink S, Van Houdt WJ, Pronk A, Van Gorp J, Siersema PD, Clevers H. Long-term expansion of epithelial organoids from human colon, adenoma, adenocarcinoma, and Barrett's epithelium. Gastroenterology. 2011; 141:1762-72. https:// doi.org/10.1053/j.gastro.2011.07.050.

30. de Miranda NF, van Dinther $M$, van den Akker BE, van Wezel T, ten Dijke P, Morreau H. Transforming growth factor $\beta$ signaling in colorectal cancer cells with microsatellite instability despite biallelic mutations in TGFBR2. Gastroenterology. 2015; 148:1427-37.e8. https:// doi.org/10.1053/j.gastro.2015.02.052.
31. Calon A, Lonardo E, Berenguer-Llergo A, Espinet E, Hernando-Momblona X, Iglesias M, Sevillano M, PalomoPonce S, Tauriello DV, Byrom D, Cortina C, Morral C, Barcelo C, et al. Stromal gene expression defines poorprognosis subtypes in colorectal cancer. Nat Genet. 2015; 47:320-9. https://doi.org/10.1038/ng.3225.

32. Kakizaki F, Sonoshita M, Miyoshi H, Itatani Y, Ito S, Kawada K, Sakai Y, Taketo MM. Expression of metastasis suppressor gene AES driven by a Yin Yang (YY) element in a CpG island promoter and transcription factor YY2. Cancer Sci. 2016; 107:1622-31. https://doi.org/10.1111/cas.13063.

33. Sato T, Vries RG, Snippert HJ, van de Wetering M, Barker N, Stange DE, van Es JH, Abo A, Kujala P, Peters PJ, Clevers H. Single Lgr5 stem cells build crypt-villus structures in vitro without a mesenchymal niche. Nature. 2009; 459:262-5. https://doi.org/10.1038/nature07935.

34. Turner N, Grose R. Fibroblast growth factor signalling: from development to cancer. Nat Rev Cancer. 2010; 10:116-29. https://doi.org/10.1038/nrc2780.

35. Palorini R, De Rasmo D, Gaviraghi M, Sala Danna L, Signorile A, Cirulli C, Chiaradonna F, Alberghina L, Papa S. Oncogenic K-ras expression is associated with derangement of the cAMP/PKA pathway and forskolinreversible alterations of mitochondrial dynamics and respiration. Oncogene. 2013; 32:352-62. https://doi. org/10.1038/onc.2012.50.

36. Palorini R, Votta G, Pirola Y, De Vitto H, De Palma S, Airoldi C, Vasso M, Ricciardiello F, Lombardi PP, Cirulli C, Rizzi R, Nicotra F, Hiller K, et al. Protein kinase A activation promotes cancer cell resistance to glucose starvation and anoikis. PLoS Genet. 2016; 12: e1005931. https://doi.org/10.1371/journal.pgen.1005931.

37. Wei Q, Costanzi S, Balasubramanian R, Gao ZG, Jacobson KA. A2B adenosine receptor blockade inhibits growth of prostate cancer cells. Purinergic Signal. 2013; 9:271-80. https://doi.org/10.1007/s11302-012-9350-3.

38. Ma DF, Kondo T, Nakazawa T, Niu DF, Mochizuki K, Kawasaki T, Yamane T, Katoh R. Hypoxia-inducible adenosine A2B receptor modulates proliferation of colon carcinoma cells. Hum Pathol. 2010; 41:1550-7. https://doi. $\operatorname{org} / 10.1016 /$ j.humpath.2010.04.008. 